\title{
Polyacrylonitile/Sulphur (PAN-S) cathode with KS6 Graphite as the conductive agent for Li-S battery
}

\author{
Wenhua Zhang ${ }^{1,3^{*}}$, Ping Liu ${ }^{2}$, Zhe Chen ${ }^{1,3}$, Ronghua Fang ${ }^{1,3}$, Dongqi Kang, 3', Zhizhao Ouyang ${ }^{1,3}$, \\ Shunhua Zhang ${ }^{1}$ \\ ${ }^{1}$ Nanchang Institute of Technology, Tianxiang Avenue No.289, 330099, Nanchang, China \\ ${ }^{2}$ State grid of Jiangxi electric power research institute, Mingqiang road No.88,330096, Nanchang, \\ China \\ ${ }^{3}$ Nanchang Institute of Technology, Jiangxi Province Key Laboratory of Precision Drive and Control, \\ Tianxiang avenue No.289, 330099, Nanchang, China \\ *E-mail: 2015994552@ nit.edu.cn
}

doi: $10.20964 / 2021.02 .41$

Received: 28 September 2020 / Accepted: 15 November 2020 / Published: 31 December 2020

\begin{abstract}
KS6 is selected as the conductive agent in this paper. Three kinds of PAN-S-KS6 composites with KS6 content of $5 \%, 10 \%$ and $20 \%$ are prepared by spray drying method. Than, the structure and electrochemical performance of the electrode are characterized, and the influence of different conductive content in the composite on the electrochemical performance of the composite electrode is also investigated by assembling lithium sulfur battery(Li-S battery). The results indicate that the ternary compounds with $10 \% \mathrm{KS} 6,40 \%$ PAN and 50\% elemental sulfur shows excellent electrochemical performance. The reason is that in PAN-S-KS6 composite, the appropriate amount of conductive agent provides good electron transport for the composite. Sufficient amount of PAN polymer can realize sulfur immobilization by complete bond of elemental sulfur, and form a complete conductive network on the surface layer of sulfur carbon composite, and the electrochemical performance of PAN-S composite electrode materials can be significantly improved.
\end{abstract}

Keywords: KS6; Conductive agent; Spray drying method; KS6-PAN-S composite; Li-S battery

\section{$\underline{\text { FULL TEXT }}$}

(C) 2021 The Authors. Published by ESG (www.electrochemsci.org). This article is an open access article distributed under the terms and conditions of the Creative Commons Attribution license (http://creativecommons.org/licenses/by/4.0/). 